\title{
JGB, VALENCIA Y LA CONVULSA EVOLUCIÓN EL URBANISMO ESPAÑOL
}

\author{
Francisco Blanc \\ Abogado \\ Valencia, España
}

Remisión artículo: 22-1-2007

Palabras Claves: Plan General de Valencia, TAU, Agente urbanizador, LRAU, Urbanismo Comparado, disociación de la Propiedad, Reglamento de Planeamiento de la Comunidad Valenciana.

La relación de JGB con la Comunidad Valenciana comenzó temprano. El Plan General de Elche fue, quizá, su primer reto importante en la práctica urbanística y, según me confesó, lo que le indujo una temprana fascinación por los temas recurrentes en los que luego trabajaría hasta el final de su vida. Es harto conocida su intervención del las Normas Subsidiarias de Elda-Petrer, también en Alicante, de donde nacieron las TAU, consagradas por la jurisprudencia del Supremo en plena Transición Política. No es extraño que en 1984 el Ayuntamiento de Valencia le contratase como consultor externo para ayudar en las tareas de revisión del Plan General, que redactaba una oficina interna, en la que yo participaba. Fue así como comenzó nuestra relación profesional, intelectual y personal.

En aquellos tiempos no existía Internet y el soporte digital no soportaba más de unos pocos $\mathrm{Mb}$. El contacto personal resultaba esencial en la transmisión del conocimiento y las comunicaciones Madrid-Valencia eran aéreas y penosas. JGB venía una vez al mes; nos adoctrinaba y al día siguiente se iba. El mismo régimen mediopensionista se le aplicó a otros consultores de la Oficina del Plan General como J. Clusa y, ocasionalmente, J. Russinés.

La gestión del suelo urbano en el Plan, era el cometido central del asesoramiento de JGB quien confrontaba cordialmente con Clusa puntos de vista diversos en interminables tertulias concluidas en la playa de la Malvarrosa donde, para espanto de los valencianos, ambos cenaban paella.

La encomienda de JGB no era un problema fácil. Un suelo urbano denso e infradotado frente a un Plan ambicioso empeñado en invertir el proceso; un ayuntamiento sin recursos frente a una Ley del Suelo de miras cicateras en lo que a renovación y conservación urbana se refiere. Es interesante que estando JGB en el asesoramiento del aquel Plan, como lo estuvo durante los tres años de su gestación, sin embargo las TAU no llegaran a aplicarse en él, al menos en su formulación originaria y ortodoxa. Los motivos de ello explican también mucho acerca de la verdadera finalidad con que fue creada esa técnica urbanística y sobre el pensamiento de quien la gestó.

En aquella época (y no sólo entonces) las TAU eran vistas, muy frecuentemente, como una simple técnica de equidistribución en suelo urbano y de obtención gratuita para la Administración de terrenos para equipamientos públicos; una especie de extensión de las bondades de la reparcelación al suelo urbano consolidado. La técnica tenía cierto glamour 
político como una aplicación políticamente rupturista o progresista de la Ley del suelo de 1976 frente a otras visiones más conservadoras de la misma. JGB tenía sin embargo una visión de mayor alcance. Las TAU malentendidas como simple promedio de plusvalías del planeamiento, podían tener efectos secundarios indeseables. En zonas urbanas densificadas por el desarrollismo de los 1960-70, los aprovechamientos promedio eran densos y extrapolarlos a los suelos de cesión conducía a encarecer su expropiación y a escasez en su obtención gratuita para los ayuntamientos. Para JGB eso era la evidente consecuencia de haber estrechado el alcance de la figura enfatizando su finalidad equidistributiva sin potenciar sus implicaciones con vistas orientadas hacia una política urbanística de recuperación urbana.

Las TAU en la versión originaria de JGB debían fijar un aprovechamiento tipo modelizado exclusivamente sobre los ejemplos históricos de ciudad deseable, particularmente pensando en la ciudad anterior a la fase hiperdensa y especulativa al pasado desarrollista entonces reciente. En otras palabras, aprovechamientos tipo moderados que gravasen con cesiones relevantes la edificación de alta densidad. La idea era disuadir la sustitución, potenciar la rehabilitación y conferir a los solares vacantes derechos de intensidad similar al del suelo urbanizable. Las TAU de JGB no concebían el Plan (General) como un documento de ordenación definitiva susceptible de producir una especie de cuenta precisa y cerrada de su potencial reparcelación, sino como un marco referencial abierto susceptible de desarrollarse con distintas alternativas de futura evolución. Dentro de esa visión, las TAU (más bien el aprovechamiento tipo) jugaban un papel directivo como elemento regulador o reconductor de las posibles alternativas. A la preguntas "¿qué ocurrirá si a la gente la da por construir de nueva planta en vez de rehabilitar?" o "con tan alto nivel de exigencia no acabará faltando suelo de cesión para ceder?". La respuesta era obvia: esa tendencia pondrá de manifiesto la necesidad de esponjamiento y reforma interior y abrirá puertas a la futura previsión de mejorar la ciudad incrementando el suelo público previsto en ella. La idea de un Plan General, que en sus funciones de alcance territorial y globalizador, incurriese en recrear visiones acabadas y estáticas del futuro urbano (como si fuera un proyecto de plan parcial de ejecución inmediata) le parecía una ingenuidad.

Esa visión de la "herramienta TAU" no tuvo éxito de acogida política en la Valencia de mediados de los 80 , por lo que JGB, que era a la hora de lo práctico era un hombre posibilista, no insistió mucho e invitó a explorar técnicas alternativas. Así se acabó implantando una modalidad de TAU, inspirada en el Plan General de Sevilla, sin aprovechamientos tipo. Es decir, cada terreno edificable aportaría la cesión de un cupo de suelo dotacional proporcional a su edificación real. (Una versión enteramente fiel a la formulación de JGB se aplicó, por ejemplo, en el Plan General de Xátiva, también en territorio valenciano).

La moda del momento era monetizar las TAU, algo que, JGB sólo consideraba interesante desde un punto de vista. Temía, no sin motivo, que sustituir las cesiones de terrenos por pagos monetarios a manos de ayuntamientos financieramente manirrotos no fuese buena idea. En cambio, sostenía la importancia de que las transferencias ponderasen la distinta valoración relativa del suelo de origen y destino aumentando o reduciendo la superficie de terreno de cesión exigible proporcionadamente. Las ideas de JGB a este respecto (no aceptar "cesiones en metálico" y ponderar las cesiones en términos de valor) sí fueron acogidas en el Plan General de Valencia. 
A la vista de lo relatado no es extraño que la visión de las TAU implantada por la Ley del Suelo de 1990 mereciera una abierta censura por parte de JGB, lo que mucha gente no entendió o atribuyó erróneamente a una supuesta evolución o cambio en sus postulados iniciales.

\section{JGB y el agente urbanizador}

A principios de los 90 JGB estaba enormemente interesado en la selección de urbanizadores por concurso al estilo previsto para el suelo "no programado" por la Ley de 1976. Este interés posiblemente venía suscitado por la inminencia de una reforma legislativa estatal y su percepción de que esa era la forma más acertada de reconducir la extendida técnica de los convenios urbanísticos en el marco de una reforma legal. Hay quien ha querido ver en ello un cambio de posiciones de JGB respecto a los tiempos de las TAU. En realidad, son dos técnicas obedientes a un mismo concepto motriz, omnipresente en toda la obra de JGB. A saber: la idea de que la incorporación a la propiedad del suelo de las rentas y plusvalías que se derivan de los planes urbanísticos conduce a un conflicto permanente entre los intereses públicos y privados, nefasto para la buena gestión del desarrollo urbano. Las TAU tratan de ser un paliativo de ese fenómeno disociando las decisiones públicas de localización de uso/aprovechamientos de sus efectos en la apropiación privada de valores del suelo. De igual modo los concursos de urbanizadores tratan de disociar la titularidad privada del suelo de la legitimación para promover su desarrollo urbanístico. Se trata, por tanto, de dos técnicas orientadas hacia un mismo objetivo y cuyas formulaciones prácticas pueden ser compatibles. De hecho JGB vislumbraba en los concursos un posible paliativo frente a la retención especulativa de solares que, en ocasiones, habían sufrido sus TAU.

Entre JGB y la Oficina del Plan General de Valencia se mantuvo el contacto tras la aprobación de éste y en este tema de los concursos de urbanizadores, sus sugerencias encontraron una coyuntura práctica donde fructificar que, a la larga, tendría enormes consecuencias.

Al comienzo de la década de los 90 el suelo urbanizable previsto en el Plan General de Valencia estaba en una situación, digamos, expectante. La experiencia de reparcelaciones a gran escala en la ciudad era escasa y en el resto de la Comunidad frustrante. Concurrían factores en la idiosincrasia local que dificultaban sensiblemente la aplicación de los conocidos sistemas de cooperación y compensación. El minifundismo extremo en la estructura de propiedad no se prestaba a constituir Juntas de Compensación e imbuía las reparcelaciones de una complejidad apabullante para la escasa capacidad gestora municipal. En el caso de Valencia hay que añadir la reticencia de muchos propietarios frente a un Plan que había recortado sensiblemente sus anteriores "aprovechamientos". En esa tesitura se abrió paso la alternativa del sistema de expropiación gestionado por concesión. La primera actuación que se desarrolla -por concurso- fue un suelo no programado en el centro urbano con importantes infraestructuras asociadas y un complejo proceso de renovación de usos. JGB -bien informado sobre la actuación- la saludó con entusiasmo aunque no sin sorpresa por la dificultad de ponerla en marcha con los hiperburocratizados procedimientos que regían por entonces. Hubo un segundo concurso en la capital y varias actuaciones similares en municipios menores del área metropolitana que siguieron el ejemplo.

A finales de 1991 el Gobierno de la Comunidad Autónoma ordenó empezar los trabajos para una reforma global de la legislación del suelo. Desde el primer momento la orientación siguió el 
enfoque de canalizar los casos de iniciativa privada por vía de concurso selectivo de urbanizadores. Las experiencias previas en la Comunidad Valenciana avalaban la utilidad de la propuesta. No por casualidad, los miembros de equipo redactor inicial teníamos o habíamos tenido una importante relación profesional y personal con JGB. Aunque al principio él no participó directamente en los trabajos de redacción de la nueva ley, su influencia en los principios de su orientación de base era notoria y las referencias personales y doctrinales a JGB eran constantes en boca de quienes originariamente participamos en aquél proyecto.

No hubo un borrador definitivo del proyecto de ley sino hasta mediados de 1993. Ello tras la difusión de un libro blanco y un largo proceso de elaboración, reflexión y debate, con la parsimonia que estas cosas requieren y que, además, exigía el compás de espera marcado por la paralela redacción del Texto Refundido de la legislación estatal de 1992. A partir de ese momento la participación de JGB (junto otro grupo selecto de urbanistas) fue directa. Cuando se le invitó a participar saludó el texto originario con entusiasmo. A su juicio era una ley de transición hacia un modelo más ambicioso que profundizase lo iniciado. Además de ser inspirador de base de las líneas maestras del texto, JGB hizo aportaciones directas respecto al sistema novedoso de clasificación de suelo (pronto derogado por la Ley estatal de 1998) y, también, al régimen legal de conservación de la edificación. La regulación de las TAU, constituía casi un homenaje.

Desde el punto de vista de JGB el resultado plasmado en aquella norma era muy discreto frente al potencial desarrollo que aún admitían sus incipientes innovaciones. A fin de cuentas seguía muy centrado en el régimen jurídico tradicional de la propiedad del suelo, salvo en lo referente a la iniciativa urbanizadora. EI entusiasmo de JGB por la ley valenciana hay que contextualizarlo en el adelanto que suponía frente a la tradición y la audacia de sus innovaciones frente al corsé impuesto por la legislación básica estatal. No se olvide que la Ley valenciana del 94, nace cuando la reglamentista ley estatal de 1992, llena de cortapisas básicas, aún no había sido masacrada por el Tribunal Constitucional. En ese contexto, el esfuerzo autonómico por disociar la propiedad del suelo del título legitimante de la iniciativa urbanizadora y por minimizar el impacto del Plan General en la generación de valores de suelo fue la aportación valorada por JGB.

Los últimos años.

Mientras el urbanismo valenciano adquiría dinámica propia y el modelo diseñado en él influenciaba otras comunidades autónomas, JGB no tuvo -que yo sepa- más contacto o influencia institucional en aquél. Sí le interesó muchísimo la experiencia aplicativa de la Ley valenciana del 94 y la difusión y estudio de la misma y sus implicaciones. Entretanto mis contactos con él se hicieron más frecuentes.

Entre la miríada de temas de estudio que abordaba a la vez hubo uno, patente en sus publicaciones y que era recurrente en nuestras pláticas: el modelo de planeamiento español. Le interesaba y preocupaba la amplia anticipación con que los planes generales atribuyen derechos edificatorios o potenciales incrementos de valor a la propiedad del suelo; los "aprovechamientos" y la dinámica de su definición a través del proceso de planeamiento, así como la función normativa de éste. 
De nuevo en este tema reaparece la misma cuestión de fondo que subyace en toda la obra de JGB y, como siempre, buscando otro enfoque adicional del problema. Creo que, en este caso, su interés lo había suscitado la embestida de la autodenominada "liberalización" que hizo temblar la tradición urbanística española, durante los 90 , sin beneficios constatados. Las acusaciones imputadas al sistema de planificación urbana español le invitaron profundizar en el estudio de los modelos comparatísticos, en su difusión y en la reflexión sobre las diferencias.

Su interés por ese tema no fue sólo filosófico sino que, como era habitual en él, se proyectó en la exploración de implicaciones prácticas. Casualmente durante su participación en la redacción de la Ley de Madrid coincidimos en el mismo problema que, en paralelo, se planteó en la elaboración del Reglamento de Planeamiento de la Comunidad Valenciana de 1998: los estándares de dotación-cesión pública y la posibilidad de generalizarlos más allá de lo previsto en el Reglamento estatal de 1978. Creo que tras su interés sobre ese tema no estaba la mera búsqueda de un nivel de dotación "científicamente óptimo", ni el prurito de incrementar las cesiones gratuitas de suelo. Más bien le interesaba la posibilidad de salvar la técnica reparcelatoria a gran escala, propia del derecho español, en un hipotético escenario de planes generales que no predefinieran aprovechamiento "medio" (ni entero), a la usanza más propia del derecho foráneo. La alternativa al "aprovechamiento tipo" (o "medio") vendría a ser un aprovechamiento más indefinido y variable (como, de hecho, lo es en la práctica recalificatoria que frecuentemente nos rodea), pero sujeto a "cesiones tipo" que, satisfaciendo todas las necesidades de suelo público -incluidos sistemas generales-, podrían restar relevancia a los incrementos o disminuciones marginales de densidad en la formación de los valores del suelo. De paso, ello solventaba la -a su juicio- perversa influencia que estaba generando la cultura de los "aprovechamientos medios" en las valoraciones expropiatorias de sistemas generales.

Esa y otras temáticas (desde el agotamiento del territorio hasta el impacto de los rascacielos pasando, cómo no, por el interesantísimo estudio histórico de la génesis del sistema español que iba realizando) le atareaban más que la evolución del derecho urbanístico positivo que, a su juicio y salvo excepciones, le parecía algo repetitiva y un tanto alambicada. Desgraciadamente el destino privó al urbanismo español de sus continuas aportaciones. 
